\title{
The Electrical Properties of Al/Methylene-Blue/n-Si/Au Schottky Diodes
}

\author{
B. Bati \\ Department of Physics, Faculty of Science, University of Yüzüncüyıl, Van, Turkey \\ Email: bahribati@hotmail.com
}

Received 24 June 2015; accepted 1 January 2016; published 6 January 2016

Copyright $@ 2016$ by authors and Scientific Research Publishing Inc.

This work is licensed under the Creative Commons Attribution International License (CC BY). http://creativecommons.org/licenses/by/4.0/

(c) (i)

\begin{abstract}
We studied the electrical characteristics of Al/methylene-blue/n-Si/Au Schottky diodes such as current-voltage, conductance-capacitance-voltage, and conductance-capacitance-frequency. We plotted rectification ratio vs. voltage (RR-V) of the diode. From $I-V$ plots of the diodes, saturation current $\left(I_{o}\right)$, and ideality factor $(n)$ were calculated. Barrier height $\left(e \Phi_{B}\right)$ and series resistance $\left(R_{S}\right)$ were calculated with Norde functions. The results show that in the Al/methylene-blue/n-Si/Au diode, the methylene-blue layer has a significant impact on electrical properties such as series resistance, barrier height, ideality factor, conductance, rectification ratio, and capacitance.
\end{abstract}

\section{Keywords}

Organic Schottky Diodes, Schottky Barrier Diodes, Methylene-Blue Layer

\section{Introduction}

It is well known that Schottky diodes with organic components have many advantages over inorganic semiconductors in electronic devices such as easy fabrication, low cost, and applicability to rigid-flexible substrates [1][4]. Many organic interfacial layers between metal and semiconductors can be prepared with simple techniques such as electrostatic spraying, spin coating, dip coating, the sol-gel technique, etc. [5]. The electrical parameters of Schottky diodes are mainly affected by the interfacial organic layer [6].

Previous studies have examined Schottky barrier diodes with different organic components. K1liçoğlu et al. studied Al/methyl-red/p-Si Schottky diodes. The structure demonstrated rectifying behavior [1] [2]. Ocak et al. studied Sn/methylene-blue/p-Si Schottky diodes. They found that the presence of this organic layer converted metal-semiconductor (MS) devices into metal-insulator-semiconductor (MIS) devices. Many studies have been done with organic interfacial layers on controlling the barrier height and minimizing the interface state [3]. Soylu et al. studied silicon-metal junctions with mixed methylene-blue and reported that the layer mixture of organ- 
ic components significantly affected electrical parameters and that to understand fully the mechanism's effect on device performance, further study of the mixture percentage was necessary [4]. Zeyrek et al. studied Al/perylene/p-Si diodes and noted that MPS-type (Metal-P-Semiconducture) SBD (Schottky barrier diode) could be used as a good electronic material combination for possible application. Modification of SBD was done with a perylene organic polymer interlayer [5].

Previous studies examined methyl-red and methylene-blue with p-Si Schottky barrier diodes [1]-[4]. This study's objective was to understand the electrical properties of n-Si Schottky diodes with methylene-blue organic components such as $\mathrm{Al} /$ methylene-blue/n-Si/Au. We examined ideality factor, series resistant, barrier height, rectification ratio, capacitance, and conductance.

\section{Experimental Procedure}

We used n-Si wafers with (100) orientation, $250 \mu \mathrm{m}$ thickness, and $\rho=10 \Omega \cdot \mathrm{cm}$ resistivity. The sample was chemically cleaned of chemical and organic contamination [7]-[9]. Samples were boiled for 20 min in RCA $\left(\mathrm{NH}_{4} \mathrm{H}+\mathrm{H}_{2} \mathrm{O}_{2}+6 \mathrm{H}_{2} \mathrm{O}\right)$ and then in $\left(\mathrm{HCl}+\mathrm{H}_{2} \mathrm{O}_{2}+6 \mathrm{H}_{2} \mathrm{O}\right)$. Afterward, they were etched in $\mathrm{HF}: \mathrm{H}_{2} \mathrm{O}(1: 10)$ for 30 seconds and rinsed in demonized water with ultrasonic vibration [10].

The ohmic contact on the back surface of the n-type Silisium (n-Si) wafer piece was fabricated by evaporating previously-cleaned $\mathrm{Au}$ [11] [12] followed by a heat treatment at $570^{\circ} \mathrm{C}$ for 30 minutes in nitrogen $\left(\mathrm{N}_{2}\right)$ atmosphere [13]. On the polished surface of the sample, a methylene-blue layer was formed using the shipping-coating method with a methylene solution of $10^{-2} \mathrm{~mol} \mathrm{~L}^{-1}$ in methanol [1]-[4]. Next, the sample was placed in the evaporation chamber to evaporate previously cleaned $\mathrm{Al}(99.99 \%)$ with $10^{-6}$ torr pressure on the front side to form a rectifying contact. The result was an Al/methylene-blue/n-Si/Au (Al/MB/n-Si) Schottky diode.

We plotted $I-V$ measurements, from the $I-V$ plot ideality factor $(n)$ and saturation current $\left(I_{o}\right)$ were calculated [11] [12]. And from $I-V$ Norde function was calculated. From Norde's functions, series resistance $\left(R_{S}\right)$ and barrier height $\left(e \Phi_{B}\right)$ were calculated [12]-[14]. We plotted the rectification ratio of this diode against voltage (RR-V) [12].

$\mathrm{G} / \mathrm{w}-\mathrm{C}-\mathrm{V}$ Measurements were performed at room temperature $\left(300^{\circ} \mathrm{K}\right)$ at $0.5 \mathrm{MHz}$ frequency and $\mathrm{G} / \mathrm{w}-\mathrm{C}-\mathrm{f}$ measurements at room temperature $\left(300^{\circ} \mathrm{K}\right)$ at $250 \mathrm{mV}$ bias. We plotted $\mathrm{G} / \mathrm{w}-\mathrm{C}-\mathrm{V}, \mathrm{C}^{-2}-\mathrm{V}$ and $\mathrm{G} / \mathrm{w}-\mathrm{C}-\mathrm{f}$ measurements of the diode (Figure 1).

\section{Results and Discussion}

When there is an insulating layer between metal-semiconductor interfaces of a metal-semiconductor device, the current-voltage $(I-V)$, according to thermionic emission theory for non-ideal condition, can be given as follows [1]-[3],

$$
I=I_{0}\left[\exp \left(\frac{e\left(V-I R_{s}\right)}{n k T}-1\right)\right]
$$

where $n$ is ideality factor, $V$ is forward bias voltage, $e$ is the electron charge, $R_{s}$ is series resistance, $k$ is the Boltzmann constant, $T$ is temperature in Kelvin, and $I_{o}$ is the saturation current derived from the straight line intercept of the $I$ axis at $V=0$ and given by

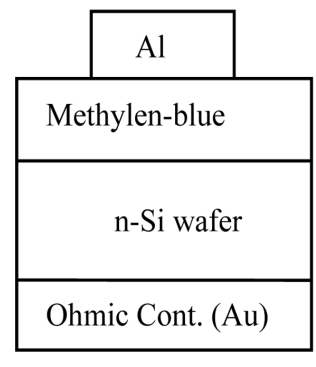

(a)

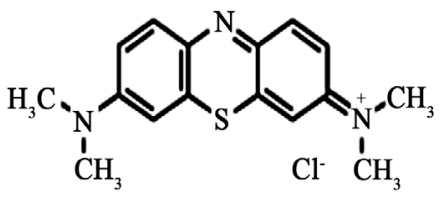

(b)

Figure 1. (a) Schematic diagram of $\mathrm{Al} / \mathrm{MB} / \mathrm{n}-\mathrm{Si}$ Schottky diode; (b) chem-

ical structure of methylene-blue [15]. 


$$
I_{0}=A R_{n}^{*} T^{2} \exp \left(-\frac{e \phi_{B}}{k T}\right)
$$

In Equation (2), $R_{n}^{*}$ is the Richardson constant (112 A/cm $\cdot \mathrm{K}^{2}$ for n-type $\mathrm{Si}$ ) [12], $A$ is the effective diode area ( $0.4 \mathrm{~mm}$ radius), and $e \Phi_{B}$ is the effective barrier height.

The ideality factor $n$ is determined from slope of the linear region of the forward bias in $I-V$ from the ratio [1]-[3]:

$$
n=\frac{e}{k T} \frac{\mathrm{d} V}{\mathrm{~d}(\ln I)}
$$

Figure 2 represents the forward bias current-voltage characteristics of the diode. For an ideal diode, the ideality factor $(n)$ equals 1 . However, the ideality factor $(n)$ in experiments can be greater than the unity [7] [9]. The ideality factor $(n)$ was obtained from the $I-V$ graph, which was 2.8 for the sample. The barrier heights $\left(e \Phi_{B}\right)$ of the Schottky diode obtained as $0.83 \mathrm{eV}$. High values of the ideality factor and barrier height imply that methylene-blue layer, native oxide layer, and contamination occurred at the metal-semiconductor interface [1]-[3].

To obtain series resistance $\left(R_{s}\right)$ and barrier height $\left(e \Phi_{B}\right)$, Norde functions were used [9] [12].

$$
F(V)=\frac{V}{\gamma}-\frac{k T}{e}\left(\frac{I(V)}{A R_{n}^{*} T^{2}}\right)
$$

$I(V)$ is the current obtained from $I-V$ measurements, $\gamma$ is an arbitrary integrated than ideality facyor $(\gamma>n)$ and the barrier height $\left(e \Phi_{B}\right)$ determined using the minimum value of $F(V)-V$ plot by means of the relationship

$$
\phi_{B}=F\left(V_{0}\right)+\frac{V_{0}}{\gamma}-\frac{k T}{e}
$$

In Equation (5), $F\left(V_{0}\right)$ is the minimum $F(V)$ value and $V_{0}$ is the voltage. The $F(V)-V$ curves of the samples are shown in Figure 3 . The series resistance $\left(R_{s}\right)$ of the diodes can be expressed as

$$
R_{s}=\frac{k T(\gamma-n)}{e I_{\min }}
$$

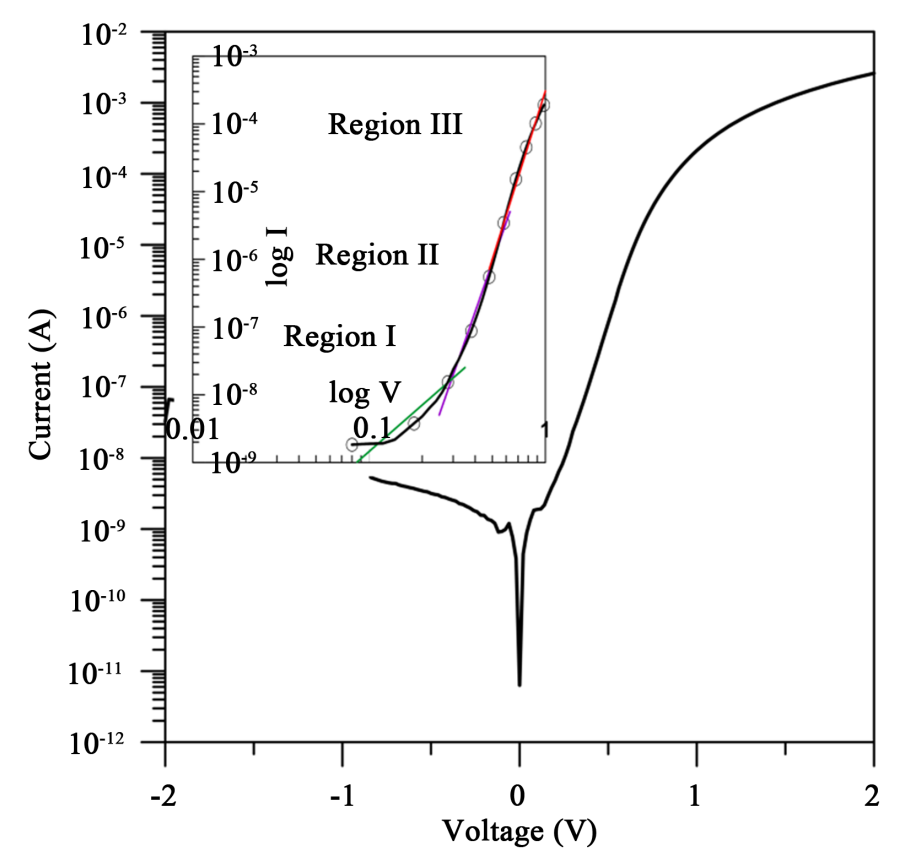

Figure 2. The forward and reverse bias current-voltage $(I-V)$ plots and the forward $\log I$ vs. $\log V(\log I-\operatorname{og} V)$ plot of the $\mathrm{Al} / \mathrm{MB} / \mathrm{n}-\mathrm{Si}$ diode. 


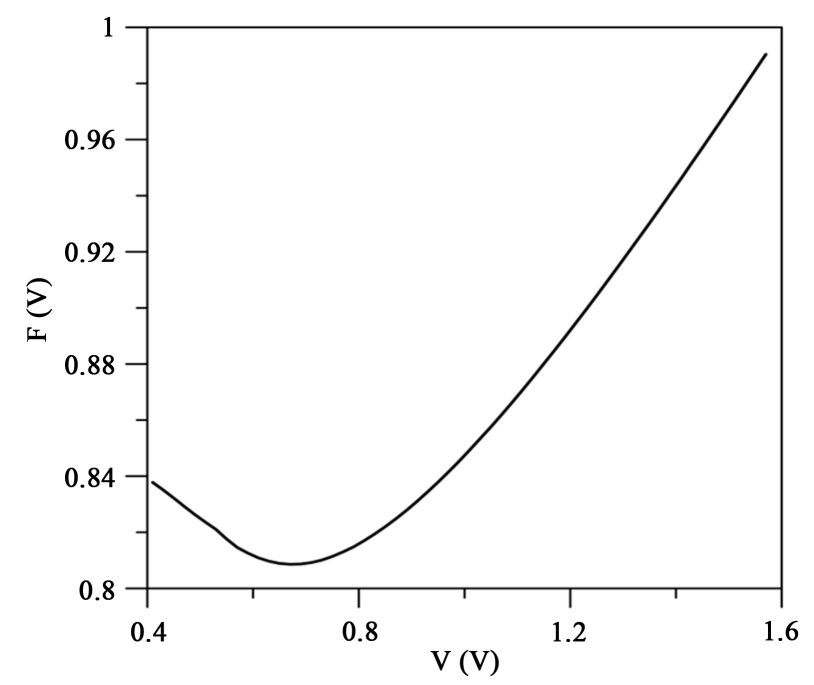

Figure 3. Norde function vs. voltage $[F(V)-V]$ for the $\mathrm{Al} / \mathrm{MB} / \mathrm{n}-\mathrm{Si}$ diode.

where $I_{\min }$ is the current value at $V_{0}$ [9] [12]. The series resistance $\left(R_{s}\right)$ and barrier height $\left(e \Phi_{B}\right)$ were obtained using Equations (5) and (6). From Norde's functions, the series resistances $\left(R_{S}\right)$ and the barrier heights $\left(e \Phi_{B}\right)$ of the Schottky diode obtained as $437 \Omega$ and $0.89 \mathrm{eV}$ respectively.

The barrier height and ideality factor of the diode were calculated as $0.83 \mathrm{eV}$ and 2.8 using Equations (2) and (3) from the y-axis intercept and the linear slope of $\ln I-V$, respectively. The ideality factor is greater than unity and shows deviation from an ideal diode. The deviation can be attributed to several effects such as the effect of organic layer, native oxide layer, contamination, and non-homogeneous interfacial (methylene) layer [8]. The barrier height is greater than MS and shows deviation from an ideal diode. The higher barrier height shows that the organic interfacial layer is a physical barrier between the metal and semiconductor. The charge transport mechanisms through the MB layer can be obtained from the analysis of the double logarithmic $(\log I-\log V)$ plot (Figure 2). The plot has three distinct regions. The slopes (m) in regions I, II, and III and were 2.3, 7.4, and 5.4, respectively. The first and the third regions correspond to low bias and low slopes, which can be characterized by the ohmic region of the MB layer. The second region with a high slope and low ideality factor can be characterized by the power law. This phenomenon is associated with two-effect, low-series resistance, and a high-injection carrier [8].

We measured the rectification ratio $(R R)$ of $\mathrm{Al} / \mathrm{MB} / \mathrm{n}-\mathrm{Si}$ Schottky diode. $R R$ is calculated from the ratio of forward and reverse current at a certain bias using equation $R R=\left|I_{b}\right| /\left|I_{r}\right|$ at $|V|=$ constant . The rectification ratio of the $\mathrm{Al} / \mathrm{MB} / \mathrm{n}-\mathrm{Si}$ is plotted as $R R-V$ in Figure 4 . The $R R$ was about $10^{5}$ at $+2 \mathrm{~V}$, which is lower than MS diodes and can be attributed to the methylene layer [12].

$\mathrm{G} / \mathrm{w}-\mathrm{V}$ and $\mathrm{C}-\mathrm{V}$ measurements of diodes were carried out at $0.5 \mathrm{MHz}$, at room temperature, and in darkness (Figure 5). When we analyze characteristics $\mathrm{G} / \mathrm{w}-\mathrm{V}$ and $\mathrm{C}-\mathrm{V}$ of diodes, the conductance and capacitance with negative voltage remained small, but with positive voltage there were conductance and capacitance peaks [3] [5]. $\mathrm{C}^{-2}-\mathrm{V}$ was plotted for $0.5 \mathrm{MHz}$ and reverse bias (Figure 5). Diffusion potential $\left(V_{0}\right)$ was obtained from the intercept of $C^{-2}-V$ with the horizontal axis. Ideality factor $(n=3.1)$ and barrier height $\left(e \Phi_{B}=0.83 \mathrm{eV}\right)$ can seen in the $\mathrm{C}^{-2}-\mathrm{V}$ graph [9].

$\mathrm{G} / \mathrm{w}-\mathrm{V}, \mathrm{G} / \mathrm{w}-\mathrm{f}$ and C-f measurements of diodes were carried out at $250 \mathrm{mV}$ at room temperature, and in darkness (Figure 6). C-f plot shows excess capacity at low frequencies. The capacity decreases at higher frequencies and is equal to the depletion region capacity at some point [9]. According to the literature, excess capacity at low frequencies is explained by either charges at the interface that cannot follow the alternative current signal or the quality of the back-ohmic contact on the bulk semiconductor substrate [9] [14].

\section{Conclusion}

The purpose of this paper was to explain the electrical properties of an $\mathrm{Al} /$ methylene-blue/n-Si/Au diode. The results show that the methylene-blue layer has a significant effect on electrical properties such as series resistance, 


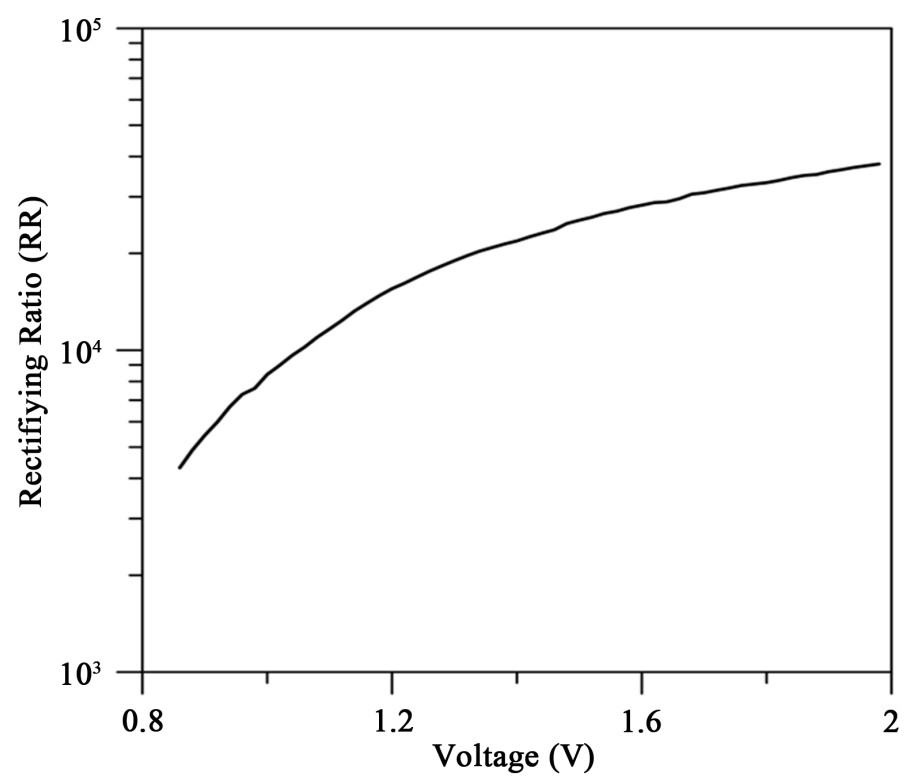

Figure 4. The rectification ratio vs. voltage $(R R-V)$ of $\mathrm{Al} / \mathrm{MB} / \mathrm{n}-\mathrm{Si}$ diode.

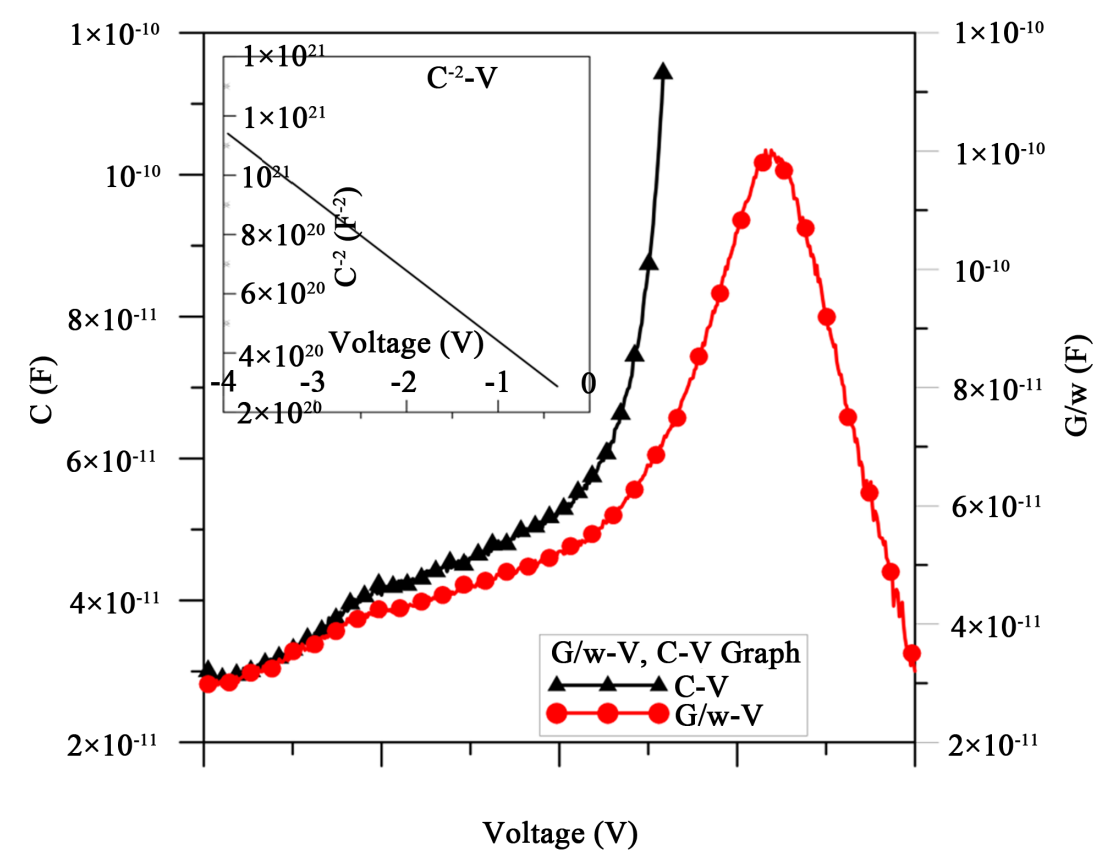

Figure 5. Conductance-Voltage $(\mathrm{G} / \mathrm{w}-\mathrm{V})$, Current-Voltage $(\mathrm{C}-\mathrm{V})$ and $\mathrm{C}^{-2}-\mathrm{V}$ for the $\mathrm{Al} / \mathrm{MB} / \mathrm{n}-\mathrm{Si}$ diode.

barrier height, ideality factor, interface state density, and capacitance of the diodes. The values of barrier height $(0.83 \mathrm{eV})$, ideality factor (2.8), and series resistance (437 $\Omega$ ) were found to be higher than a typical MS. High values imply that the methylene-blue layer, native oxide layer, and contamination occurred at the metal-semiconductor interface.

When we analyze characteristics of $\mathrm{G} / \mathrm{w}-\mathrm{V}$ and $\mathrm{C}-\mathrm{V}$ of diodes, the conductance and capacitance with negative voltage remain small, but with positive voltage peaks of conductance and capacitance occur.

The rectification ratio of the $\mathrm{Al} /$ methylene-blue/n-Si/Au was plotted as RR-V. The diode's RR was about $10^{5}$ at $+2 \mathrm{~V}$, which was lower than that of other MS diodes and could be attributed to methylene blue layer. 


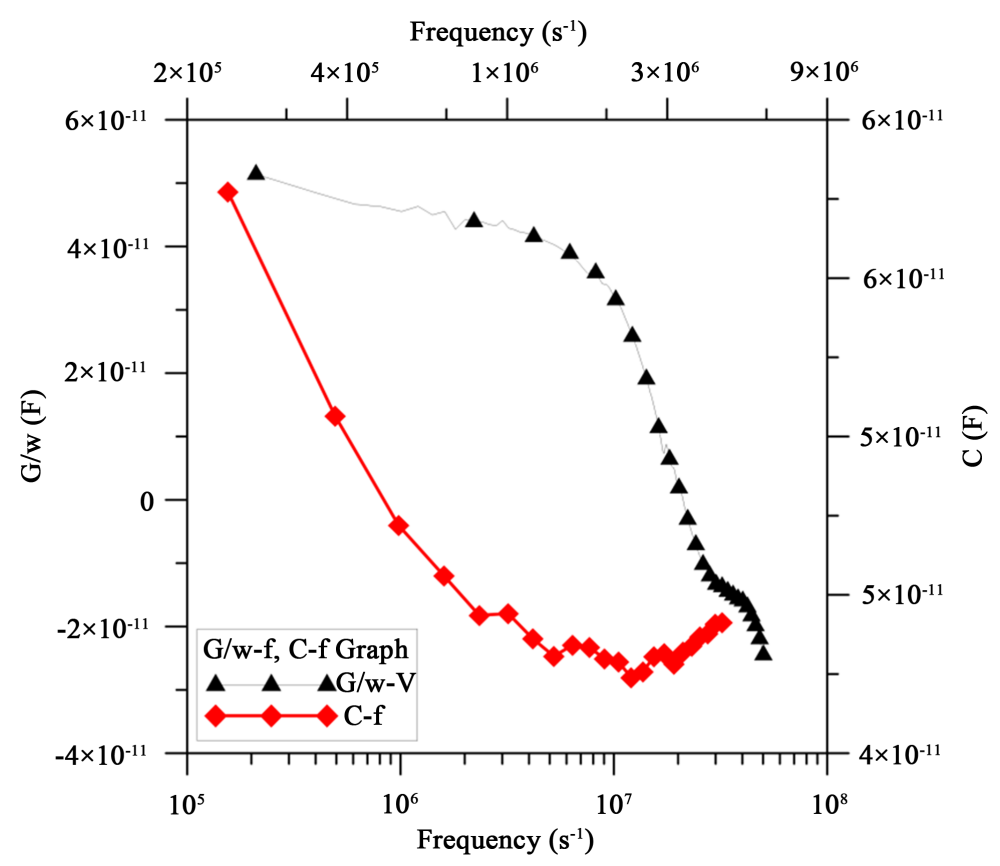

Figure 6. Conductance-frequency $(\mathrm{G} / \mathrm{w}-\mathrm{f})$ and capacitance-frequency $(\mathrm{C}-\mathrm{f})$ for the $\mathrm{Al} / \mathrm{MB} / \mathrm{n}-\mathrm{Si}$ diode.

The capacitance-frequency shows excess capacitance at low frequencies. We infer that interface states can follow a signal at low frequencies.

\section{References}

[1] Kılıçoğlu, T., Aydın, M.E. and Ocak, Y.S. (2007) Physica B: Condensed Matter, 388, 244-248. http://dx.doi.org/10.1016/j.physb.2006.06.126

[2] Kılıçoğlu, T. (2008) Thin Solid Films, 516, 967-970. http://dx.doi.org/10.1016/j.tsf.2007.06.022

[3] Ocak, Y.S., Kulakçı, M., Kılıçoğlu, T., Turan, R. and Akkılıç, K. (2009) Synthetic Metals, 159, 1603-1607. http://dx.doi.org/10.1016/j.synthmet.2009.04.024

[4] Soylu, M., Al-Hartomy, O.A., Al Said, S.A.F., Al-Ghamdi, A.A., Yahia, I.S. and Yakuphanoglu, F. (2013) Microelectronics Reliability, 53, 1901-1906. http://dx.doi.org/10.1016/j.microrel.2013.05.008

[5] Zeyrek, S., Acaroğluş, E., Altındal, Ş., Birdoğan, S. and Bülbül, M.M. (2013) Current Applied Physics, 13, $1225-1230$. http://dx.doi.org/10.1016/j.cap.2013.03.014

[6] Bülbül, M.M., Zeyrek, S., Altındal, Ş. and Yüzer, H. (2006) Microelectronic Engineering, 83, 577-581. http://dx.doi.org/10.1016/j.mee.2005.12.013

[7] Yüksel, Ö.F., Tuğluoğlu, N., Gülveren, B., Şafak, H. and Kuş, M. (2013) Journal of Alloys and Compounds, 577, 3036. http://dx.doi.org/10.1016/j.jallcom.2013.04.157

[8] Gupta, R.K. and Singh, R.A. (2004) Materials Chemistry and Physics, 86, 279-283. http://dx.doi.org/10.1016/j.matchemphys.2004.03.003

[9] Readdy, V.R. (2014) Thin Solid Films, 556, 300-306. http://dx.doi.org/10.1016/j.tsf.2014.01.036

[10] Liou, B.W. (2013) Thin Solid Films, 545, 509-513.

[11] Yahia, I.S., Farag, A.A.M., Yakuphanoğlu, F. and Farrooq, W. A. (2011) Synthetic Metal, 161, 880-887.

[12] Farag, A.A.M. and Yahia, I.S. (2011) Synthetic Metals, 161, 32-39. http://dx.doi.org/10.1016/j.synthmet.2010.10.030

[13] Zhu, M.G., Zhang, J. and Hou, H.N. (2012) Microelectronic Engineering, 95, 112-115.

[14] Soylu, M. (2011) Material Science in Semiconductor Processing, 14, 212-218.

[15] http://en.wikipedia.org/wiki/metheyelene 